Article

\title{
A Durable and Self-Cleaning Superhydrophobic Surface Prepared by Precipitating Flower-Like Crystals on a Glass-Ceramic Surface
}

\author{
Haiqing $\mathrm{Fu}^{1,2,3}$, Shuo Liu ${ }^{1,3}$, Lanlin $\mathrm{Yi}^{1,2,3}$, Hong Jiang ${ }^{1,2,3}$, Changjiu $\mathrm{Li}^{1,2,3, *}$ and \\ Yongjun Chen ${ }^{2,3}$ \\ 1 Special Glass Key Lab of Hainan Province, Haikou 570228, China; fuhaiqing18@sina.com (H.F.); \\ lshuo1@outlook.com (S.L.); yilanlin20@gmail.com (L.Y.); jianghong@hainanu.edu.cn (H.J.) \\ 2 State Key Laboratory of Marine Resource Utilization in South China Sea, Hainan University, Haikou 570228, \\ China; yongchen@hainanu.edu.cn \\ 3 College of Materials Science and Engineering, Hainan University, Haikou 570228, China \\ * Correspondence: lichangjiu@hainanu.edu.cn; Tel.: +86-186-8958-9458
}

Received: 23 February 2020; Accepted: 30 March 2020; Published: 2 April 2020

\begin{abstract}
Herein, a superhydrophobic surface with superior durability was fabricated on a glass-ceramic surface by crystallization, hydrofluoric acid (HF) etching, and surface grafting. The as-prepared glass-ceramic surface was composed of three-dimensional flower-like micro-clusters, which were self-assembled from numerous nanosheets. Such a dual-scale rough surface exhibited superhydrophobicity, with a water contact angle (WCA) of $170.3^{\circ} \pm 0.1^{\circ}$ and a sliding angle (SA) of $\sim 2^{\circ}$ after grafting with $1 \mathrm{H}, 1 \mathrm{H}, 2 \mathrm{H}, 2 \mathrm{H}$-perfluorodecyltriethoxysilane (FAS-17). This can be attributed to the synergistic effect between the dual-scale structure and surface chemistry. Furthermore, this surface exhibited excellent self-cleaning properties, stability against strong acid and strong alkali corrosion, and anti-stripping properties.
\end{abstract}

Keywords: glass-ceramic; crystallization; dual-scale roughness; superhydrophobic; durable; self-cleaning

\section{Introduction}

Inspired by the "lotus effect" in nature, numerous biomimetic superhydrophobic surfaces have been widely studied [1-4]. Superhydrophobicity is an extreme wetting phenomenon, which can be distinguished by measuring the contact angle (CA). The CA is the angle $(\theta)$ between the solid-liquid interface and the gas-liquid interface tangent at the solid-liquid-gas three-phase interface (Figure 1a). A value of $\theta$ is greater than $150^{\circ}$ corresponds to superhydrophobicity [5,6]. Superhydrophobic surfaces have a wide range of application prospects for self-cleaning [7-9], anti-icing [10], anti-corrosion [9,10], oil-water separation [11,12], anti-fogging [13,14], and drag reduction [15,16].

Low surface energy and micro-nanostructures of a rough surface are the main determinants of superhydrophobicity [17]. Therefore, a superhydrophobic surface can be obtained by either (1) modification of a rough substrate via low surface energy or (2) fabrication of a rough surface on a low-surface-energy substrate [18]. Currently, superhydrophobic surfaces are fabricated by several preparation techniques, such as sol-gel [19], templating [20], chemical vapor deposition (CVD) [21], electrospinning [21,22], laser/plasma etching [7,23,24], and phase separation [25]. For instance, Xue et al. [19] constructed a dual-scale surface roughness by coating fibers with titania sol and demonstrated an optimal superhydrophobicity with a water contact angle (WCA) of $154.0^{\circ} \pm 0.5^{\circ}$. Ma et al. [21] proposed a combination of electrospinning and CVD to prepare superhydrophobic fabrics with a WCA of $175^{\circ}$ and a sliding angle (SA) $<2.5^{\circ}$. Wang et al. [23] utilized picosecond laser pulses 
and fabricated a superhydrophobic solar glass by constructing a groove-shaped array on the glass surface, obtaining a CA of $156^{\circ}$. Gao et al. [24] designed a superhydrophobic surface by fabricating leaf-like clusters on a zinc surface by the plasma etching technique and demonstrated a WCA of $158^{\circ}$ and an $\mathrm{SA}<5^{\circ}$.
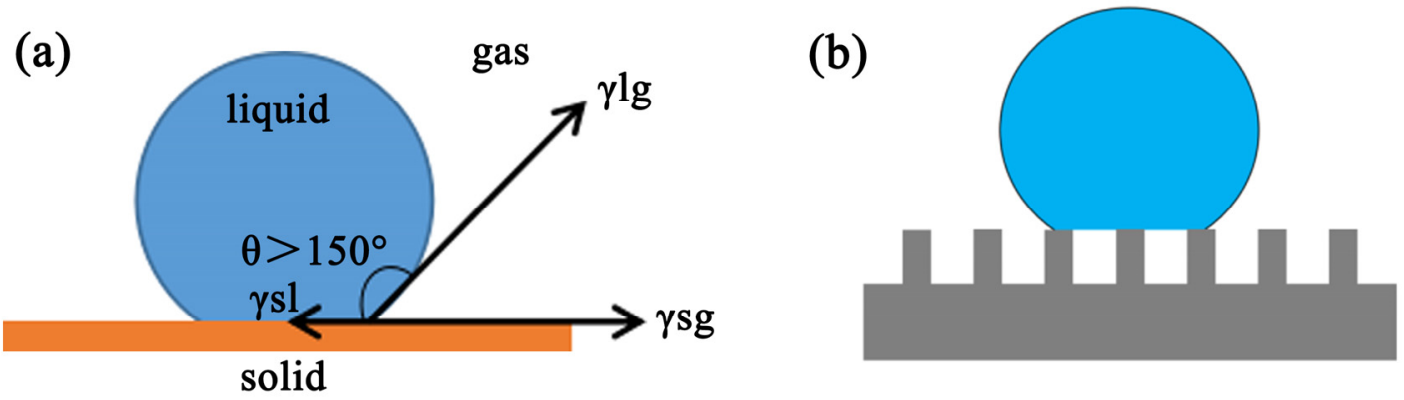

Figure 1. (a) Schematic of a superhydrophobic surface, (b) Cassie-Baxter model.

It is well known that glass-ceramic exhibits high mechanical strength, excellent corrosion resistance, desirable abrasive resistance, and high thermal stability [26-28]. Recently, our group has successfully prepared a superhydrophobic glass-ceramic surface, with an irregular porous coral-like structure, which demonstrated a WCA of $152^{\circ}$ and an SA of $<5^{\circ}$ [29]. However, the size and distribution of the crystals were found to be different on the surface. The surface roughness and fine structure were not well controlled. Based on this, we used $\mathrm{Cr}_{2} \mathrm{O}_{3}$ as the crystal-nucleating agent and nepheline as the basic microcrystalline system to prepare a superhydrophobic glass-ceramic surface with controllable and finer three-dimensional structure.

Herein, we choose $\mathrm{Cr}_{2} \mathrm{O}_{3}$ as a nucleating agent, which can form octahedral crystal nucleus. Then, nepheline crystals were grown vertically on the outer surface of the octahedron to form a flower-like structure. The superhydrophobic glass-ceramic surfaces were prepared in two steps. In the first step, a flower-like structure was precipitated on the glass-ceramic surface by heat treatment, which was subsequently treated with hydrofluoric acid (HF) to corrode the glass phase and obtain a certain roughness by exposing the crystals. In the second step, the glass-ceramic surface was grafted with $1 \mathrm{H}$, $1 \mathrm{H}, 2 \mathrm{H}, 2 \mathrm{H}$-perfluorodecyltriethoxysilane (FAS-17) to obtain a superhydrophobic surface. The results revealed that the as-prepared glass-ceramic surface possesses a dual-scale hierarchical microstructure and exhibits a WCA of $170.3^{\circ} \pm 0.1^{\circ}$ and a SA of $\sim 2^{\circ}$ after surface grafting. Moreover, the surface exhibits excellent self-cleaning properties, stability against strong acid and strong alkali corrosion, and anti-stripping properties. Furthermore, the mechanism of superhydrophobic self-cleaning behavior was explained based on the Cassie-Baxter model (Figure 1b). In this model, the grooves absorb a large amount of air, which reduces the solid-liquid contact area and effectively prevents water droplets from penetrating into the grooves.

\section{Experimental}

\subsection{Materials}

In this study, a $\mathrm{Na}_{2} \mathrm{O}-\mathrm{Al}_{2} \mathrm{O}_{3}-\mathrm{SiO}_{2}$ based glass-ceramic system was investigated. The raw materials, including sodium carbonate $\left(\mathrm{Na}_{2} \mathrm{CO}_{3} \geq 99.5 \%\right)$, magnesium oxide $(\mathrm{MgO} \geq 98.0 \%)$, aluminum oxide $\left(\mathrm{Al}_{2} \mathrm{O}_{3} \geq 99.0 \%\right)$, silica $\left(\mathrm{SiO}_{2} \geq 99.0 \%\right)$, potassium carbonate $\left(\mathrm{K}_{2} \mathrm{CO}_{3} \geq 99.0 \%\right)$, ferric oxide $\left(\mathrm{Fe}_{2} \mathrm{O}_{3} \geq 99.0 \%\right)$, chromic oxide $\left(\mathrm{Cr}_{2} \mathrm{O}_{3} \geq 99.0 \%\right)$, and FAS-17 ( $\left.\geq 96.0 \%\right)$ were purchased from Macklin Biochemical Co., Ltd., Shanghai, China. Calcium carbonate $\left(\mathrm{CaCO}_{3} \geq 99.0 \%\right)$, boric acid $\left(\mathrm{H}_{3} \mathrm{BO}_{3} \geq 99.5 \%\right), \mathrm{HF}(40.0 \%)$, and ethanol $\left(\mathrm{C}_{2} \mathrm{H}_{5} \mathrm{OH} \geq 99.8 \%\right)$ were obtained from Xilong Chemical Co., Ltd., Guangzhou, China. 


\subsection{Fabrication of a Superhydrophobic Glass-Ceramic Surface}

Table 1 presents the chemical composition of the investigated glass-ceramic. The completely mixed reagent powders were melted in an alumina crucible at $1350{ }^{\circ} \mathrm{C}$ for $2 \mathrm{~h}$ to obtain a homogeneous molten glass. Then, the melt was poured into water to obtain a glass frit, followed by crushing and milling. A cylindrical glass sample was obtained by pressing the glass powder under a uniaxial pressure of $5 \mathrm{MPa}$ and then was placed on an alumina substrate for subsequent thermal treatment.

Table 1. Chemical composition of the studied glass-ceramic.

\begin{tabular}{cccccccccc}
\hline Oxide & $\mathrm{SiO}_{2}$ & $\mathrm{Al}_{2} \mathbf{O}_{3}$ & $\mathrm{CaO}$ & $\mathrm{MgO}$ & $\mathrm{K}_{\mathbf{2}} \mathrm{O}$ & $\mathrm{Fe}_{2} \mathrm{O}_{3}$ & $\mathrm{Na}_{\mathbf{2}} \mathrm{O}$ & $\mathbf{B}_{2} \mathrm{O}_{3}$ & $\mathrm{Cr}_{\mathbf{2}} \mathrm{O}_{3}$ \\
\hline Amount (mol.\%) & 50.31 & 15.58 & 2.05 & 3.8 & 2.08 & 0.24 & 19.91 & 5.12 & 0.91 \\
\hline
\end{tabular}

The heat-treated glass-ceramic surface was etched in a 5 vol.\% HF solution for $30 \mathrm{~s}$ to expose the crystals. Then, the HF-etched samples were immersed into a $2 \mathrm{wt} . \%$ ethanol solution of FAS- 17 at $60^{\circ} \mathrm{C}$ for $2 \mathrm{~h}$ and dried in an oven for $2 \mathrm{~h}$ at $120^{\circ} \mathrm{C}$ to obtain fluorinated surfaces [23,29]. Figure 2 illustrates the preparation of a durable superhydrophobic glass-ceramic surface.

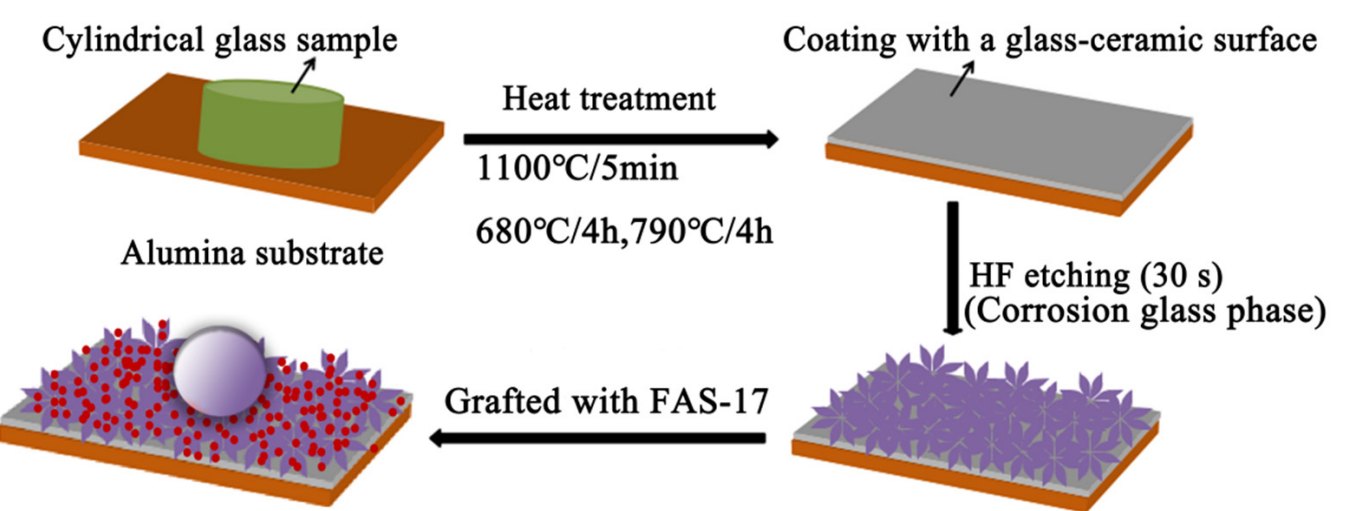

Superhydrophobic glass-ceramic surface Flower-like crystal structures exposed to glass surface

Figure 2. Schematic illustration of the preparation of a durable superhydrophobic glass-ceramic surface.

\subsection{Material Characterization}

Glass transition temperature $\left(T_{g}\right)$, crystallization temperature $\left(T_{c}\right)$, and melting point $\left(T_{m}\right)$ were measured by differential thermal analysis (DTA, NETZSCH STA449F5, Selb, Germany) in a nitrogen atmosphere. The DTA curve was obtained by heating in the range from 40 to $1250{ }^{\circ} \mathrm{C}$ at a heating rate of $10{ }^{\circ} \mathrm{C} \mathrm{min}{ }^{-1}$. The crystalline phase of the glass-ceramic was determined by X-ray diffraction (XRD, Bruker D8 Advance X, Aachen, Germany) with $\mathrm{CuK} \alpha$ radiation. The XRD pattern was obtained in the diffraction angles $(2 \theta)$ range of 15 to $75^{\circ}$, with a step size of $0.02^{\circ}$. The microstructure of the glass-ceramic was characterized by a field emission scanning electron microscope (FESEM, Hitachi S-4800, Tokyo, Japan) equipped with an energy-dispersive spectrometry (EDS) system. The three-dimensional structure was measured by a laser scanning confocal microscope (VK-X250K, Keyence, Osaka, Japan). The chemical composition was analyzed by EDS and X-ray photoelectron spectroscopy (XPS, ESCALAB 250Xi, Waltham, MA, USA). The WCA and SA were measured by using an optical contact angle meter (Drop meter A-100, Ningbo, China). Each surface was measured at five different points with a water droplet of $\sim 5 \mu \mathrm{L}$. 


\section{Results and Discussion}

\subsection{Crystallization Behavior}

Figure 3a presents the DTA curve of the parent glass, showing an exothermic crystallization peak at $790{ }^{\circ} \mathrm{C}$. The DTA curve indicates that the $T_{g}$ and $T_{m}$ were $\sim 680^{\circ} \mathrm{C}$ and $\sim 1090^{\circ} \mathrm{C}$, respectively. Based on the DTA results, the nucleation and crystallization temperature of glass-ceramic were $680{ }^{\circ} \mathrm{C}$ and $790{ }^{\circ} \mathrm{C}$, respectively. Figure $3 \mathrm{~b}$ shows the XRD pattern of a glass-ceramic sample nucleated at $680{ }^{\circ} \mathrm{C}$ for $4 \mathrm{~h}$ and crystallized at $790^{\circ} \mathrm{C}$ for $4 \mathrm{~h}$, confirming the presence of the nepheline phase (PDF\#35-0424).
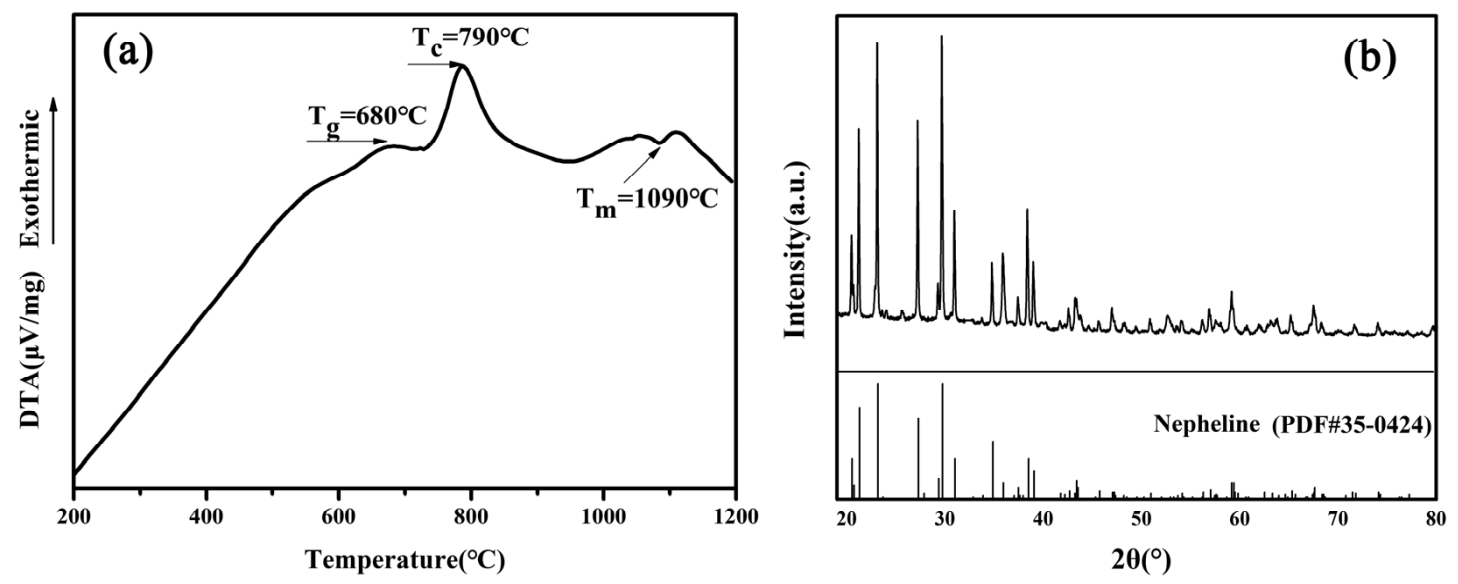

Figure 3. (a) DTA curve of the parent glass and (b) XRD pattern of a glass-ceramic sample nucleated at $680{ }^{\circ} \mathrm{C}$ for $4 \mathrm{~h}$ and crystallized at $790{ }^{\circ} \mathrm{C}$ for $4 \mathrm{~h}$. $\left(T_{g}\right)$ : transition temperature, $\left(T_{c}\right)$ : crystallization temperature, $\left(T_{m}\right)$ : melting point.

\subsection{Analysis of Surface Morphology}

Figure 4 shows the samples nucleated at $680^{\circ} \mathrm{C}$ for $2 \mathrm{~h}, 4 \mathrm{~h}$, and $12 \mathrm{~h}$. The crystal nuclei of the octahedra were precipitated after nucleation for $2 \mathrm{~h}$, and the main components were $\mathrm{Cr}$ and $\mathrm{O}$ (Figure 4a and Figure S1). The nepheline crystals began to grow vertically on the outer surface of the octahedron after nucleation for $4 \mathrm{~h}$ (Figure $4 \mathrm{~b}$ ). The length of the nepheline crystal reached $400 \mathrm{~nm}$ after nucleation for $12 \mathrm{~h}$ (Figure 4c). The EDS pattern indicated that the vertically grown crystals were nepheline, because their main components were $\mathrm{Na}, \mathrm{Al}$, and $\mathrm{Si}$, as for nepheline (Figure S2).
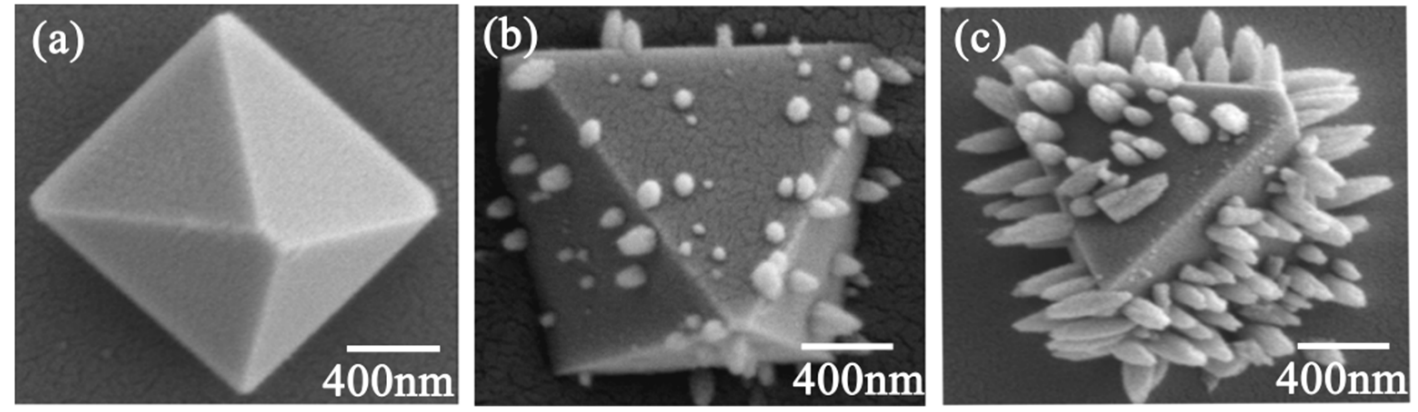

Figure 4. SEM images of samples nucleated at $680^{\circ} \mathrm{C}$ for (a) $2 \mathrm{~h}$, (b) $4 \mathrm{~h}$, and (c) $12 \mathrm{~h}$.

After nucleation at $680^{\circ} \mathrm{C}$ for $4 \mathrm{~h}$, the nepheline crystals began to precipitate on the outer surface of the octahedral nuclei. (Figure $4 \mathrm{~b}$ ). Therefore, we established a heat treatment system to observe the crystal growth process by nucleation at $680{ }^{\circ} \mathrm{C}$ for $4 \mathrm{~h}$ and crystallization at $790{ }^{\circ} \mathrm{C}$ for different times. Before SEM observation, the glass phase was corroded with an HF solution (5 vol.\%) for $30 \mathrm{~s}$ to expose the nepheline crystals. Figure 5 exhibits SEM images of the glass-ceramic surface. It can be readily observed that the micro-clusters, with a special flower-like structure, were composed of 
numerous sheet-like nanocrystals. Moreover, variation in crystal growth was observed by varying the crystallization time. For instance, after the crystallization for $0.5 \mathrm{~h}$ (Figure 5a), a large number of microplates self-assembled into several micro-flowers. Once the crystallization time reached $1 \mathrm{~h}$, numerous sheet-like nanocrystals and micro-flowers were observed on the glass-ceramic surface (Figure 5b). A further increase in crystallization time led to an increase in the surface density of micro-clusters and nanosheets (Figure 5c). When the crystallization time was close to $4 \mathrm{~h}$, large and continuous flower-like micro-clusters, covering the entire surface of the glass-ceramic, were observed (Figure 5d). After HF etching and FAS-17 grafting, the WCA values of the sample surfaces crystallized for $0.5,1,2$, and $4 \mathrm{~h}$ were $145.6^{\circ} \pm 2.9^{\circ}, 151.4^{\circ} \pm 1.3^{\circ}, 155.5^{\circ} \pm 0.5^{\circ}$, and $170.3^{\circ} \pm 0.1^{\circ}$, respectively (Figure 5), and the root-mean-square surface roughness (RMS) of the samples after crystallization for $0.5 \mathrm{~h}, 1 \mathrm{~h}, 2 \mathrm{~h}$, and $4 \mathrm{~h}$ were $1.746 \mu \mathrm{m}, 2.196 \mu \mathrm{m}, 2.357 \mu \mathrm{m}$, and $2.810 \mu \mathrm{m}$, respectively (Figure S3). As the crystallization time increased, the flower clusters became larger and larger, leading to an increase in surface roughness. Therefore, the WCA also increased with the increase of crystallization time after HF etching and FAS-17 grafting. Noteworthy, grafting with FAS-17 only reduced the surface energy of glass-ceramic and did not change its structure.
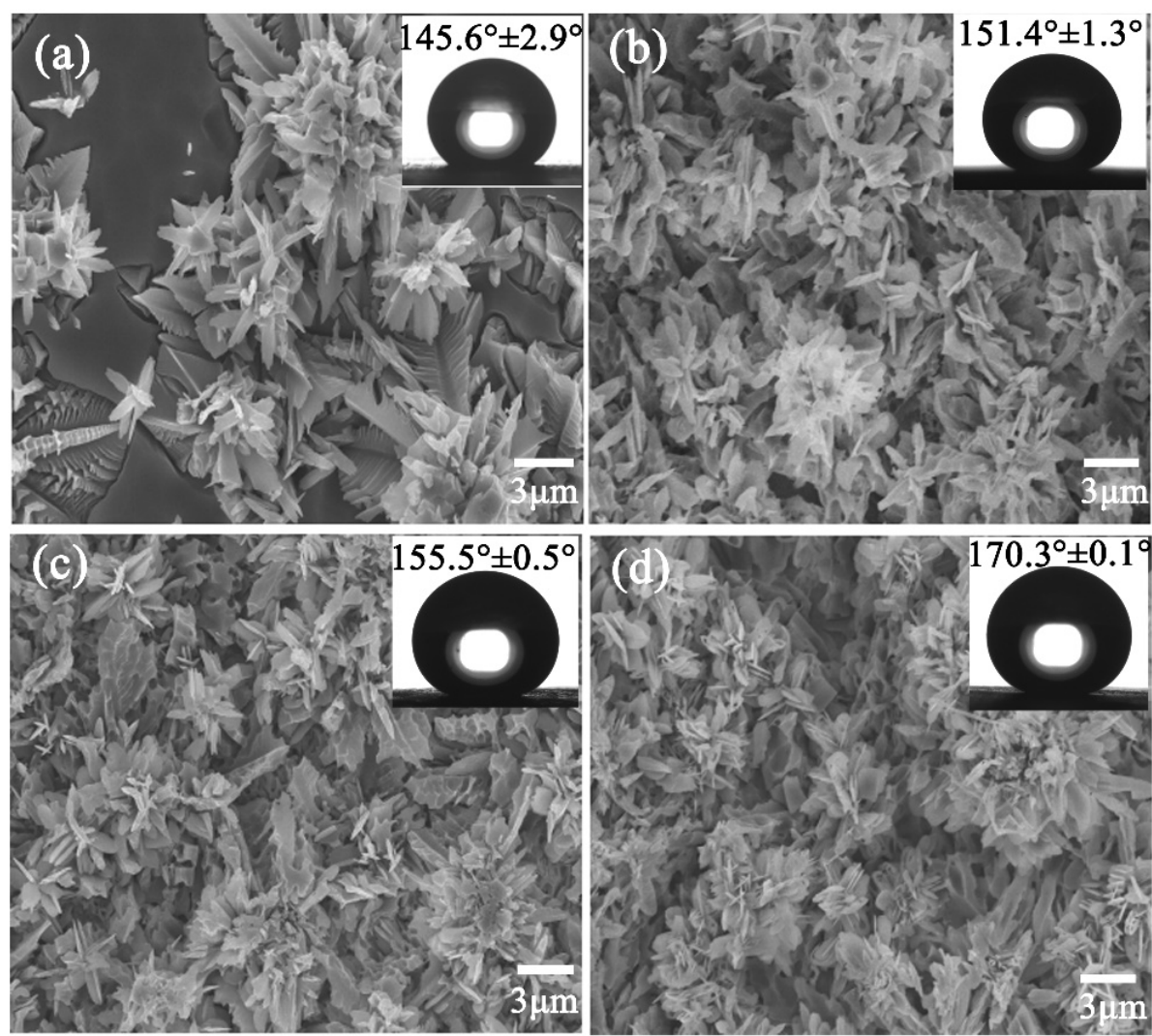

Figure 5. SEM images of the samples nucleated at $680{ }^{\circ} \mathrm{C}$ for $4 \mathrm{~h}$ and crystallized at $790{ }^{\circ} \mathrm{C}$ for (a) $0.5 \mathrm{~h}$, (b) $1 \mathrm{~h},(\mathbf{c}) 2 \mathrm{~h}$, and (d) $4 \mathrm{~h}$. The inset shows the water contact angle (WCA) values for different crystallization times.

Figure 6 presents SEM images of a single flower-like micro-cluster and a single flower-like structure. Overall, the morphology of glass-ceramic surface was characterized by flower-like micro-clusters, with lateral dimension of 2 to $15 \mu \mathrm{m}$, as shown in Figures $5 \mathrm{~d}$ and 6a. These micro-clusters self-assembled from a large number of flower-like structures. Moreover, numerous nanosheets self-assembled to form flower-like structure with a length of 0.1-2 $\mu \mathrm{m}$ and width of 50-900 nm (Figure 6b). These results clearly show that the glass-ceramic surface had a dual-scale hierarchical structure, where the first layer consisted of micron-scale protrusions, and the second layer contained nano-scale features. It is worth 
emphasizing that the observed dual-scale microstructure was able to capture air and F groups, which resulted in high WCA.
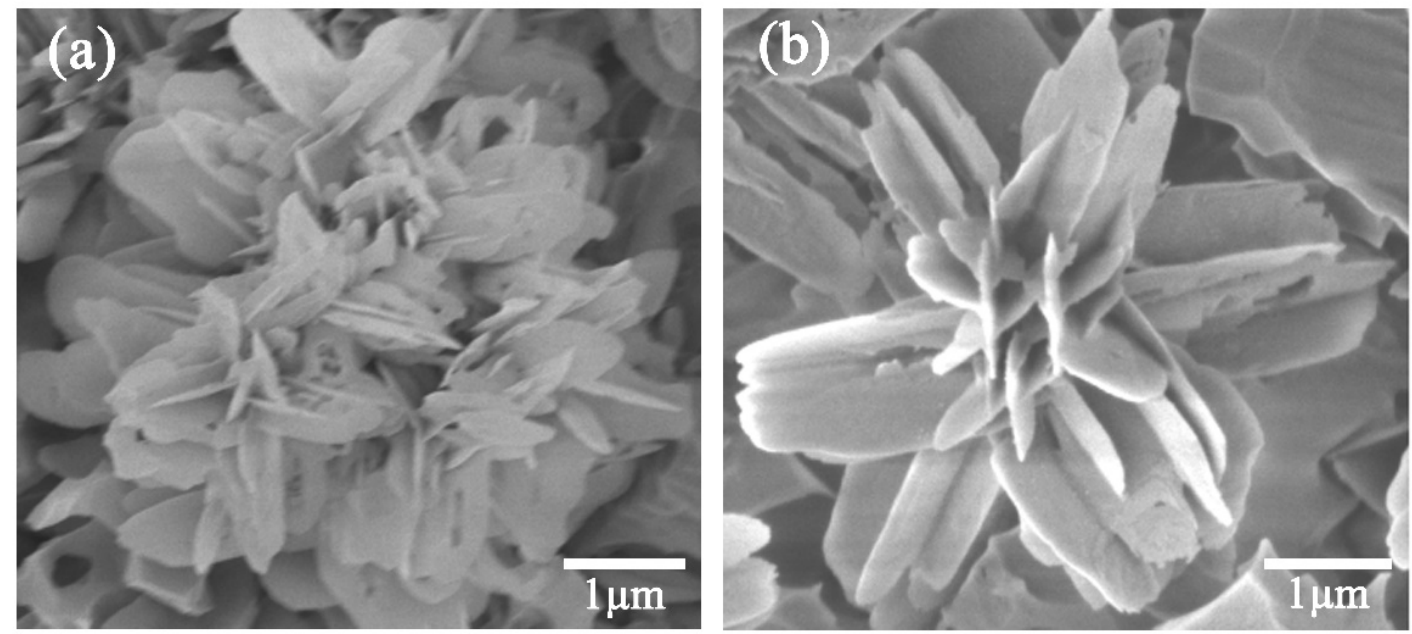

Figure 6. SEM images of (a) a single flower-like micro-cluster and (b) a single flower-like structure after nucleation at $680^{\circ} \mathrm{C}$ for $4 \mathrm{~h}$ and crystallization at $790^{\circ} \mathrm{C}$ for $4 \mathrm{~h}$.

\subsection{Surface Wettability and Self-Cleaning Properties}

Figure 7a-d presents the WCA of original and HF-etched glass-ceramic surfaces. The WCA of the original glass-ceramic surface was $24.9^{\circ}$, indicating the hydrophilic nature of the original surface (Figure 7a). However, the WCA of the FAS-17-grafted original glass-ceramic surface increased to $97.5^{\circ}$ (Figure 7b), which indicates that roughness plays a critical role in superhydrophobicity. On the other hand, the HF-etched glass-ceramic surface exhibited superhydrophilicity, with a WCA of $0^{\circ}$ (Figure 7c). Compared to the original glass-ceramic surface, the exposed crystals of the HF-etched glass-ceramic surface increased the surface roughness and provided superhydrophilicity [30]. In contrast, when the HF-etched glass-ceramic surface was grafted with FAS-17, a WCA of $170.3^{\circ} \pm 0.1^{\circ}$ was achieved due to low surface energy and dual-scale roughness (Figure $7 \mathrm{~d}$ ). Therefore, it can be concluded that the superhydrophobic surface was the result of a combination of surface roughness and low surface energy. Herein, the surfaces were nucleated at $680{ }^{\circ} \mathrm{C}$ for $4 \mathrm{~h}$ and crystallized at $790{ }^{\circ} \mathrm{C}$ for $4 \mathrm{~h}$, then etched in an HF solution ( $5 \mathrm{vol} . \%$ ) for $30 \mathrm{~s}$. Figure $7 \mathrm{e}-\mathrm{k}$ presents the process of water droplet approach, contact, deformation, and detachment for the HF-etched and FAS-17-grafted glass-ceramic surfaces. The water droplet retained its typical spherical shape after contacting the glass-ceramic surface and easily separated from the surface. Figure 71 shows the sliding process of the water droplet $(7 \mu \mathrm{L})$ on the surface, demonstrating the superhydrophobicity of the surface, with a low SA of $\sim 2^{\circ}$. Obviously, the as-prepared glass-ceramic surface showed low adhesion.

Figure 8 shows the process of self-cleaning of the superhydrophobic glass-ceramic surface. Glass powder was used as a model pollutant. A layer of pollutant was sprinkled on the superhydrophobic glass-ceramic surface tilted at an angle of $\sim 5^{\circ}$. When distilled water droplets $(\sim 50 \mu \mathrm{L})$ came in contact with the contaminated surface, the pollutant became attached to the water droplets and was removed (Figure 8a-d), resulting in a cleaned glass-ceramic surface (Figure 8e). Moreover, the water droplet maintained its spherical shape even after absorbing the pollutants. This result clearly revealed the self-cleaning behavior of the superhydrophobic glass-ceramic surface. 
(a) $24.9^{\circ} \quad(\mathrm{b})$

$97.5^{\circ}(\mathrm{c})$

$0^{\circ}$

(d) $170.3^{\circ} \pm 0.1^{\circ}$
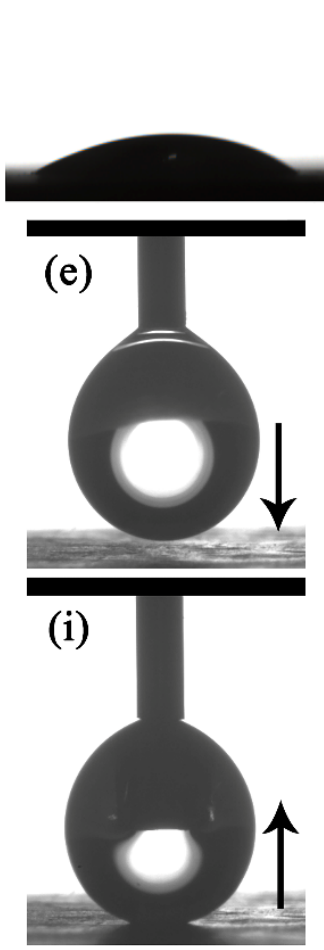

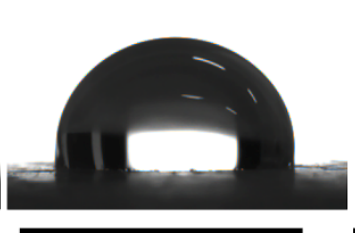

(f)
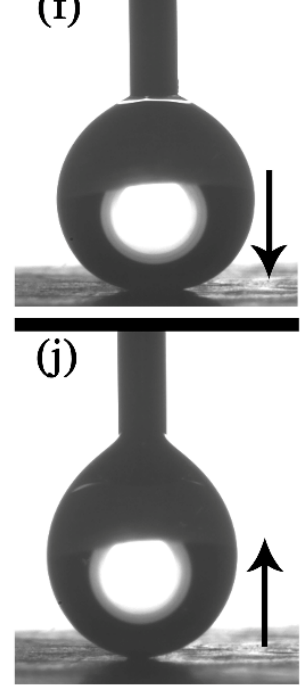
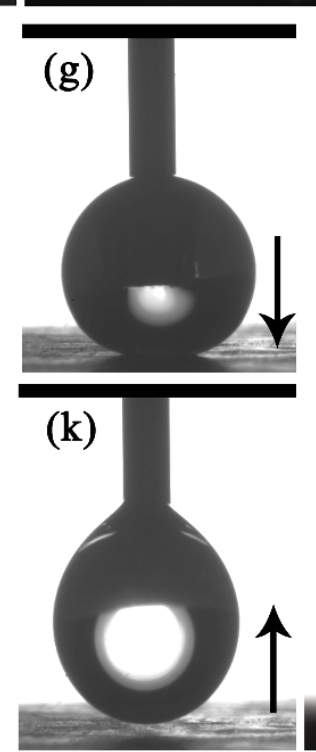
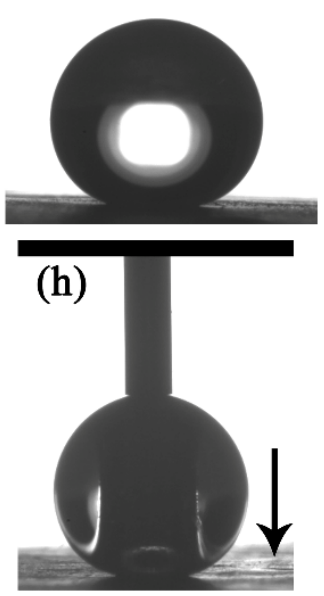

(1)

Figure 7. Optical images of the WCA on glass-ceramic surfaces: (a) original glass-ceramic surface; (b) $1 \mathrm{H}, 1 \mathrm{H}, 2 \mathrm{H}, 2 \mathrm{H}$-perfluorodecyltriethoxysilane (FAS-17)-grafted original glass-ceramic surface; (c) hydrofluoric acid (HF)-etched glass-ceramic surface; and (d) HF-etched and FAS-17-grafted glass-ceramic surface; (e-k) process of water droplet approach, contact, deformation, and detachment for HF-etched and FAS-17-grafted glass-ceramic surfaces. The arrow represents the direction of movement of the needle; (1) a water droplet sliding on the surface.
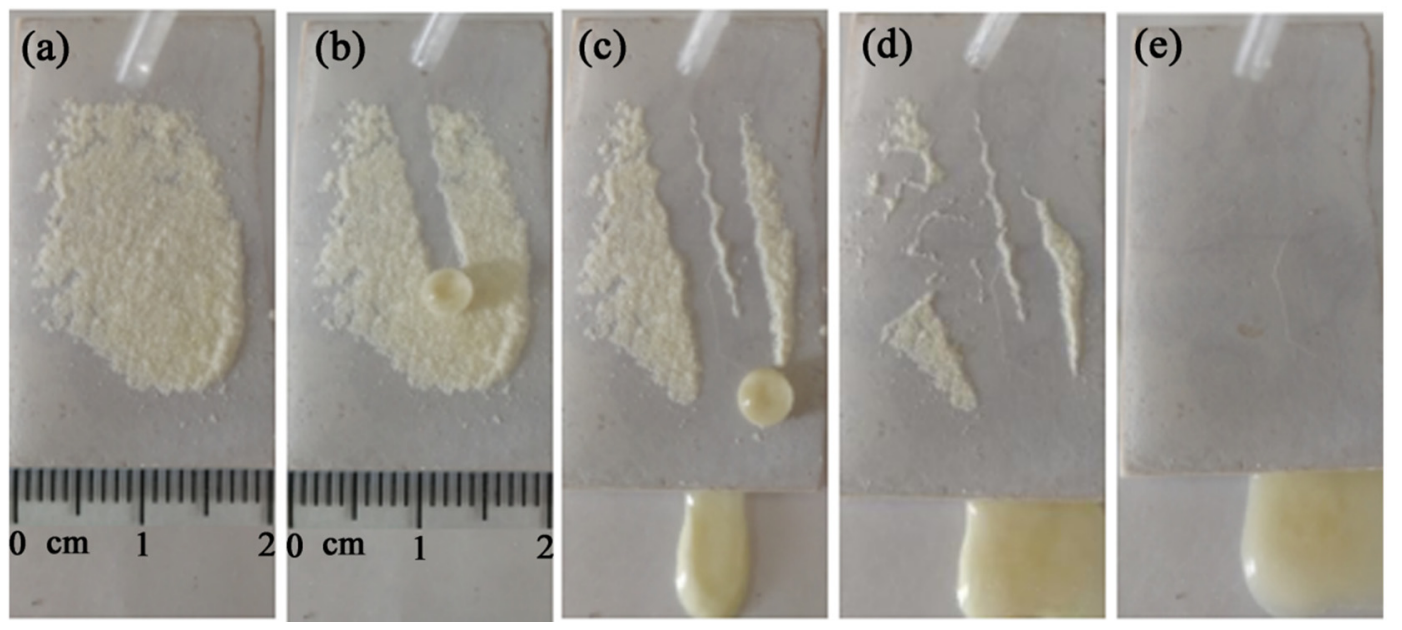

Figure 8. (a-e) Self-cleaning process of the superhydrophobic glass-ceramic surface.

For the comprehensive understanding of the self-cleaning performance of the superhydrophobic sample surface with a flower-like microstructure, we described the WCA using the Cassie-Baxter Equation as follows [31]:

$$
\operatorname{Cos} \theta_{A}=f_{1} \operatorname{Cos} \theta-f_{2}
$$


where $\theta_{\mathrm{A}}\left(170.3^{\circ}\right)$ and $\theta\left(97.5^{\circ}\right)$ represent the WCA of the flower-like and the original glass-ceramic surfaces grafted with FAS-17, respectively; and $f_{1}$ and $f_{2}$ refer to the fractional area of the flower-like structure and that of the air between the structural voids, respectively (i.e., $f_{1}+f_{2}=1$ ). Equation (1) shows that the WCA of the flower-like surface $\left(\theta_{\mathrm{A}}\right)$ increased with an increasing fraction of air $\left(f_{2}\right)$. Based on Equation (1), the $f_{2}$ value of the flower-like surface was found to be 0.9835 , indicating that air accounted for $\sim 98.35 \%$ of the contact area between the flower-like structure and the water droplets. This result shows that the dual-scale structure plays a critical role in the superhydrophobicity of glass-ceramic surfaces. Moreover, the presence of a dual-scale microstructure also explains the excellent self-cleaning performance of glass-ceramic surfaces.

Equations (2) and (3) show the mechanism of hydrolysis and condensation of compounds, respectively [32-35]. The reaction process between FAS-17 and the glass-ceramic substrate involves hydrolysis and condensation and can be divided into three steps (Figure 9). In the first step, the fluoroalkylsilane is hydrolyzed to form siloxanes. In the second step, the siloxanes are condensed to form oligosiloxanes. Finally, the $\mathrm{Si}-\mathrm{OH}$ in the oligomers form hydrogen bonds with the $\mathrm{OH}$ groups on the glass-ceramic substrate and covalent bonds with the glass-ceramic substrate during drying and curing [36]. As a result, low-surface-energy groups were successfully grafted onto the glass-ceramic.

$$
\begin{gathered}
\text { Hydrolysis : } \mathrm{M}(\mathrm{OR})_{\mathrm{n}}+\mathrm{nH}_{2} \mathrm{O} \rightarrow \mathrm{M}(\mathrm{OH})_{\mathrm{n}}+\mathrm{nROH} \\
\text { Condensation : } \mathrm{M}(\mathrm{OH})_{\mathrm{n}} \rightarrow \mathrm{MO}_{\mathrm{n} / 2}+\mathrm{n} / 2 \mathrm{H}_{2} \mathrm{O}
\end{gathered}
$$

(1)

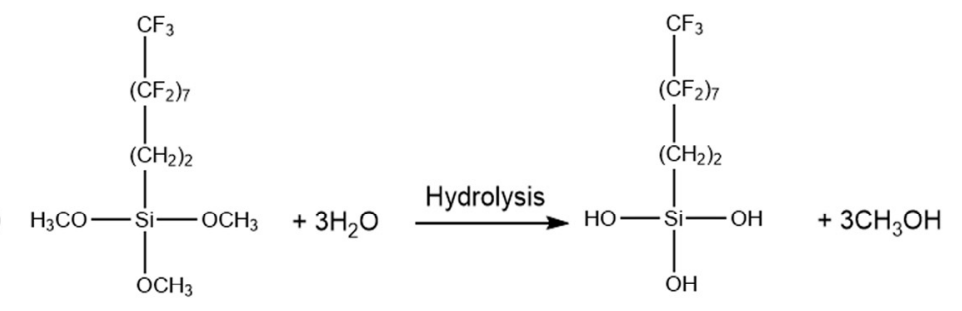

(2)

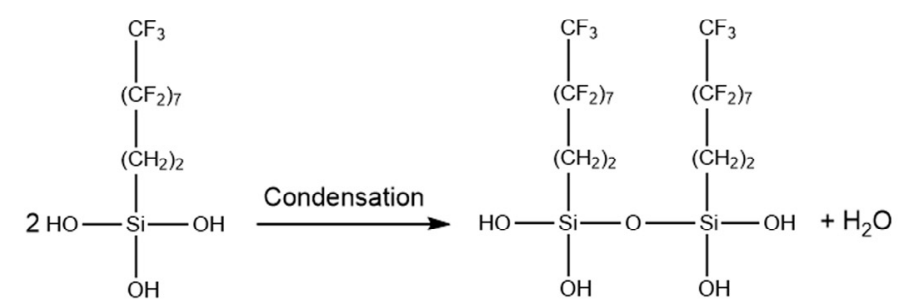

(3)

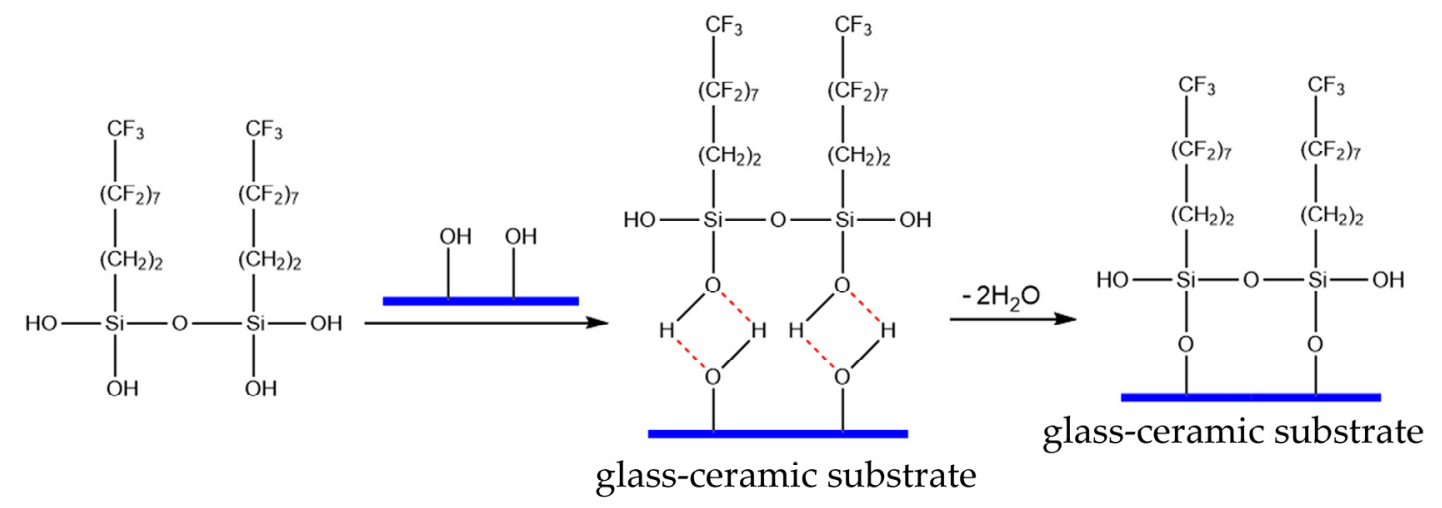

Figure 9. The reaction process between FAS-17 and glass-ceramic. 


\subsection{Surface Chemical Composition}

Furthermore, EDS was employed to analyze the composition of the glass-ceramic surface. The as-prepared sample surface mainly contained $\mathrm{O}, \mathrm{Cr}, \mathrm{Na}, \mathrm{Al}$, and $\mathrm{Si}$, as shown in Figure $\mathrm{S} 4$. However, the FAS-17-grafted glass-ceramic surface exhibited the presence of $\mathrm{F}$ as well, which indicated the successful implantation of FAS-17 on the glass-ceramic.

The state of the F element was further analyzed by XPS (Figure 10a-c). The as-prepared glass-ceramic surface mainly contained $\mathrm{O} 1 \mathrm{~s}, \mathrm{C} 1 \mathrm{~s}, \mathrm{Si} 2 \mathrm{~s}$, and $\mathrm{Si} 2 \mathrm{p}$ peaks (Figure 10a), which were located at binding energies of 532.6, 284.7, 155.0, and $103.2 \mathrm{eV}$, respectively. The FAS-17-grafted glass-ceramic surface contained an additional peak of $\mathrm{F} 1 \mathrm{~s}$ at $689.1 \mathrm{eV}$ (Figure 10a,c), indicating the presence of $F$ groups on the grafted glass-ceramic surface. Figure $10 \mathrm{~b}$ presents high-resolution $\mathrm{C} 1 \mathrm{~s}$ spectra of the glass-ceramic surfaces. The $C 1$ s spectrum of the FAS-17-grafted glass-ceramic surface showed three peaks, located at the binding energies of 285.2, 291.3, and $294.1 \mathrm{eV}$, which can be ascribed to $\mathrm{C}-\mathrm{H}, \mathrm{C}-\mathrm{CF}_{2}$, and $\mathrm{C}-\mathrm{CF}_{3}$ bonds [23,37], respectively. It is well known that, among these three groups, the surface energy of $\mathrm{C}-\mathrm{CF}_{3}$ is the lowest $\left(6 \mathrm{mN} \mathrm{m}^{-1}\right)$, followed by that of $\mathrm{C}-\mathrm{CF}_{2}$ [38]. The presence of the $\mathrm{C}-\mathrm{CF}_{3}$ and $\mathrm{C}-\mathrm{CF}_{2}$ groups reduced the surface energy, leading superhydrophobicity. XPS analysis further confirmed the successful grafting of FAS-17 on the sample.
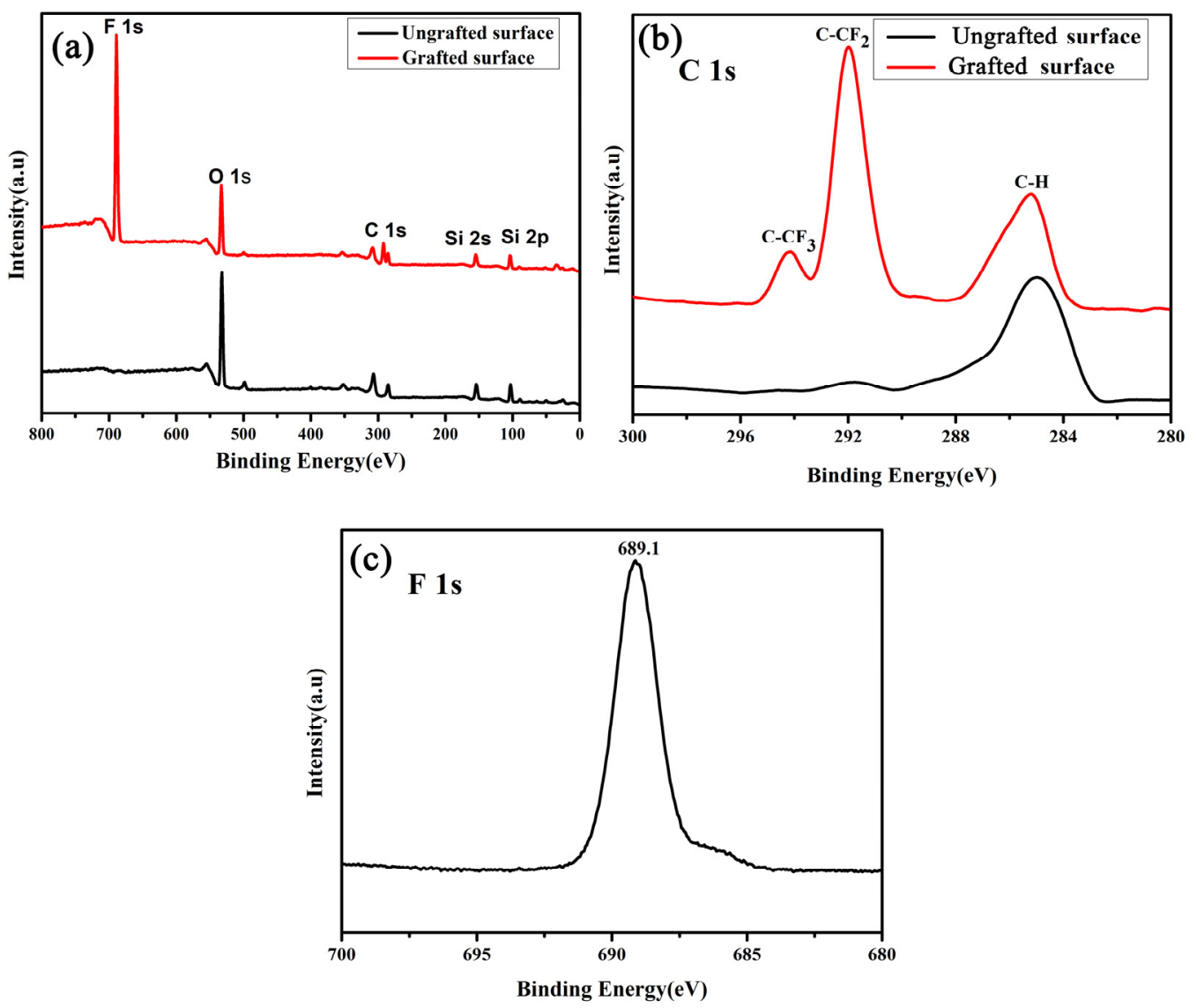

Figure 10. (a) Wide-range, (b) high-resolution C 1s and (c) F 1s XPS spectra of the glass-ceramic surfaces.

\subsection{Surface Durability Test}

Durability of a superhydrophobic surface is indispensable for its practical applications. Therefore, several tests were carried out to evaluate the durability of the glass-ceramic surface. In practical applications, a superhydrophobic surface may come into contact with strong acids or bases. The FAS-17-grafted glass-ceramic surface exhibited superior stability against aqueous $\mathrm{H}_{2} \mathrm{SO}_{4}(\mathrm{pH}=1)$ and aqueous $\mathrm{NaOH}(\mathrm{pH}=14)$ (Figure 11). Figure 11 shows digital photographs of water droplets 
with different $\mathrm{pH}$ on the superhydrophobic glass-ceramic surface. Distilled water was dyed with methyl orange to determine the $\mathrm{pH}$ of the solution based on the color change. These droplets showed a spherical shape on the glass-ceramic surface. The as-prepared superhydrophobic glass-ceramic surface appeared uniform (Figure 11a) and resistant to the attack of the strong acid and alkali (Figure 11b). Herein, the volume of each water droplet was $\sim 50 \mu \mathrm{L}$. Figure 11c presents the changes of WCA after the samples were immersed in $\mathrm{H}_{2} \mathrm{SO}_{4}$ and $\mathrm{NaOH}$ solutions $(\mathrm{pH}=1,3,5,7,9,11,14)$ for $48 \mathrm{~h}$, showing that the WCA remained above $165^{\circ}$ for the different $\mathrm{pH}$ of the water droplets.
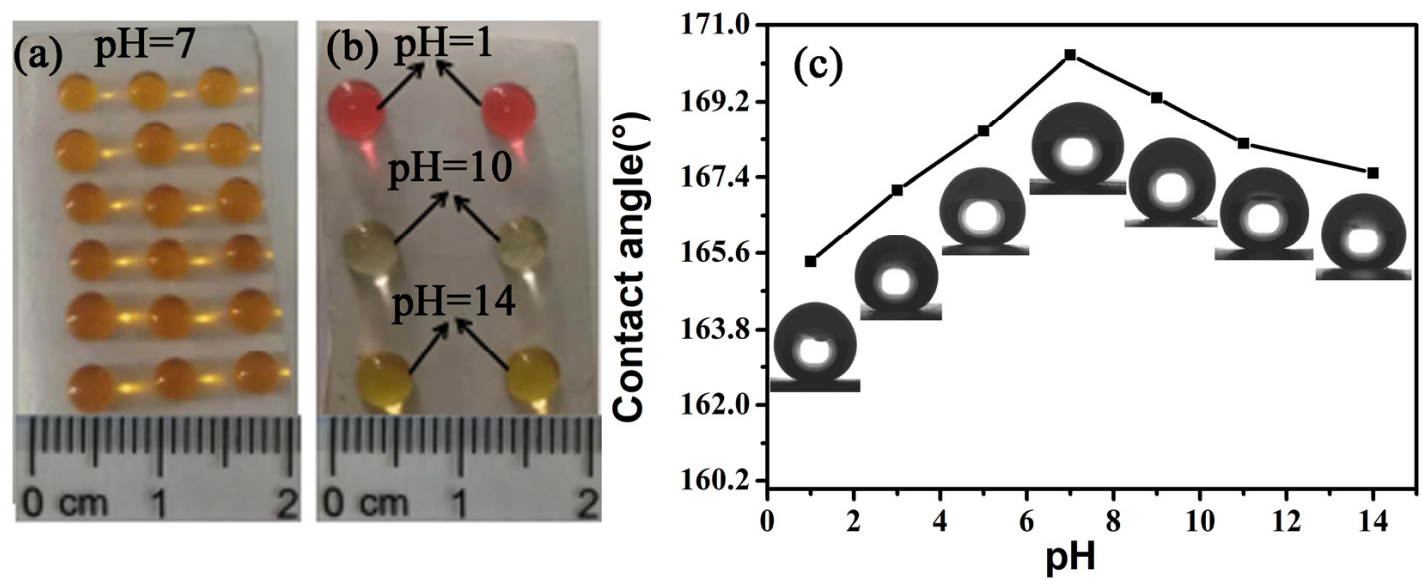

Figure 11. (a,b) Digital photographs of water droplets with different $\mathrm{pH}$ on the superhydrophobic glass-ceramic surface and (c) changes of WCA after the samples were immersed in $\mathrm{H}_{2} \mathrm{SO}_{4}$ and $\mathrm{NaOH}$ solutions $(\mathrm{pH}=1,3,5,7,9,11,14)$ for $48 \mathrm{~h}$.

Furthermore, the durability of the superhydrophobic glass-ceramic surface was demonstrated by the tape peeling test. After peeling for 10 and 20 times with 3M scotch tape (cat. 600), the glass-ceramic surfaces still maintained their special flower-like structure, and the WCA remained higher than $167^{\circ}$ (Figure 12).
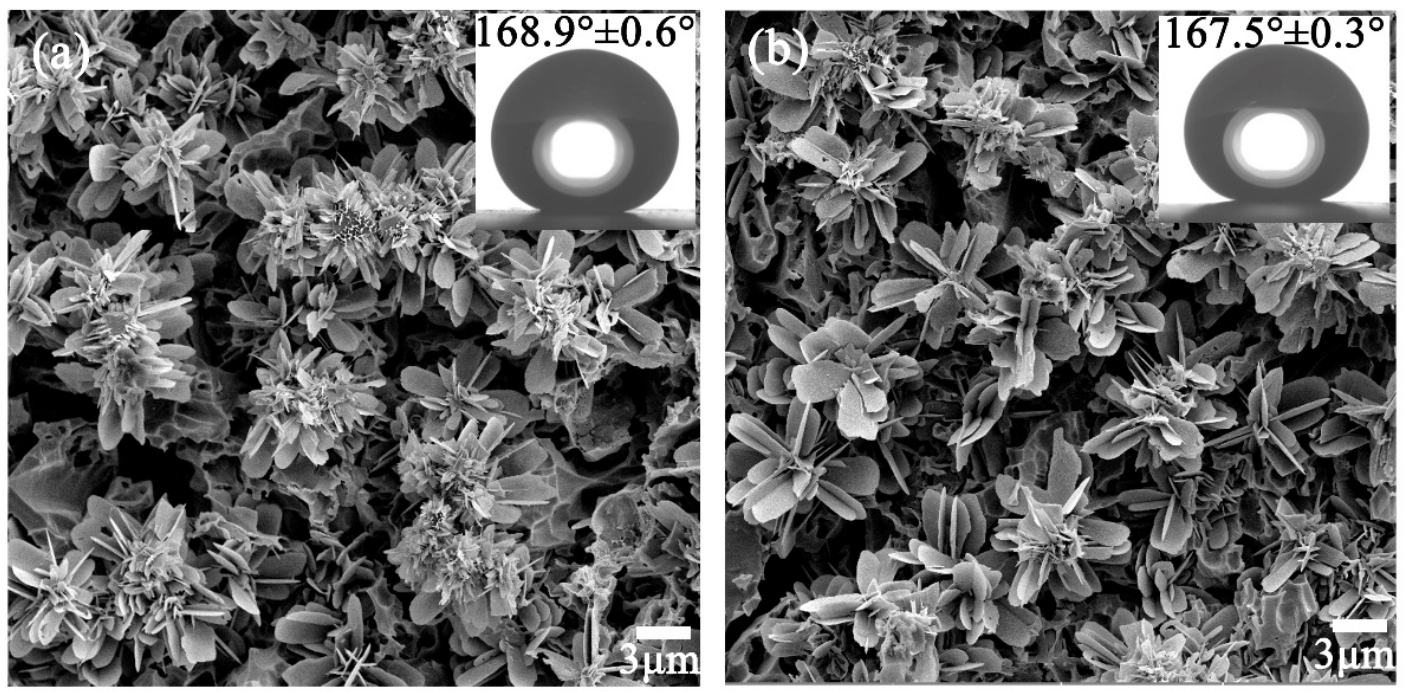

Figure 12. SEM images after peeling for (a) 10 and (b) 20 times with 3M scotch tape. Inset: WCA values.

\section{Conclusions}

In summary, a superhydrophobic glass-ceramic surface was fabricated by sequential crystallization, HF etching, and FAS-17 grafting. The as-prepared glass-ceramic surface was found to be composed of complex flower-like micro-clusters, which self-assembled from numerous nanosheets, showing 
a dual-scale hierarchical structure at the micro-/nanoscale. This dual-scale hierarchical structure is advantageous for capturing air to decrease the solid-liquid interface and for adsorbing more $F$ groups to decrease the surface energy. The FAS-17-grafted glass-ceramic surface exhibited superior superhydrophobicity, with a WCA of $170.3^{\circ} \pm 0.1^{\circ}$ and a SA of $\sim 2^{\circ}$. Moreover, excellent self-cleaning performance and durability were also observed. The excellent properties of superhydrophobic glass-ceramic surfaces demonstrate the potential of glass-ceramic materials for a wide array of industrial applications, such as the fabrication of superhydrophobic glass-ceramic glazes for ceramic tiles and building materials.

Supplementary Materials: The following are available online at http://www.mdpi.com/1996-1944/13/7/1642/s1; Figure S1. (a) The sample was nucleated at $680^{\circ} \mathrm{C}$ for $2 \mathrm{~h}$, (b) EDS pattern marked with square in (a); Figure S2. (a) The sample was nucleated at $680{ }^{\circ} \mathrm{C}$ for $12 \mathrm{~h}$, (b) EDS pattern marked with square in (a); Figure S3. Three-dimensional images of the samples nucleated at $680^{\circ} \mathrm{C}$ for $4 \mathrm{~h}$ and crystallized at $790^{\circ} \mathrm{C}$ for (a) $0.5 \mathrm{~h}$, (b) $1 \mathrm{~h}$, (c) $2 \mathrm{~h}$, and (d) $4 \mathrm{~h}$, where (e), (f), (g), and (h) are the high-magnification (150X) three-dimensional images of the regions in (a), (b) (c), and (d), respectively; Figure S4. EDS patterns of ungrafted and FAS-17-grafted glass-ceramic surfaces.

Author Contributions: Conceptualization, H.F.; Writing-original draft preparation, H.F. and S.L.; Investigation, Y.C. and H.J.; Formal analysis, H.F. and L.Y.; Writing-review and editing, H.F. and C.L.; Supervision, C.L. All authors have read and agreed to the published version of the manuscript.

Funding: This work was supported by the Natural Science Foundation of Hainan Province (519MS022); Key Scientific \& Technological Project of Hainan Province (ZDKJ2017011); Special funds for guiding local scientific and technological development by China government (ZY2019HN0904); The National Key Research and Development Program of China (2016YFC0700804); The Natural Science Foundation of China (51562008).

Conflicts of Interest: The authors declare no conflict of interest.

\section{References}

1. Gao, X.; Jiang, L. Biophysics: Water-repellent legs of water striders. Nature 2004, 432, 36. [CrossRef] [PubMed]

2. Gao, X.; Yan, X.; Yao, X.; Xu, L.; Zhang, K.; Zhang, J.; Yang, B.; Jiang, L. The dry-style antifogging properties of mosquito compound eyes and artificial analogues prepared by soft lithography. Adv. Mater. 2007, 19, 2213-2217. [CrossRef]

3. Guo, Z.; Liu, W. Biomimic from the superhydrophobic plant leaves in nature: Binary structure and unitary structure. Plant Sci. 2007, 172, 1103-1112. [CrossRef]

4. Bixler, G.D.; Bhushan, B. Bioinspired rice leaf and butterfly wing surface structures combining shark skin and lotus effects. Soft Matter 2012, 8, 11271-11284. [CrossRef]

5. Feng, X.; Jiang, L. Design and creation of superwetting/antiwetting surfaces. Adv. Mater. 2006, 18, 3063-3078. [CrossRef]

6. Martin, S.; Bhushan, B. Transparent, wear-resistant, superhydrophobic and superoleophobic poly (dimethylsiloxane) (PDMS) surfaces. J. Colloid Interface Sci. 2017, 488, 118-126. [CrossRef]

7. Ta, D.V.; Dunn, A.; Wasley, T.J.; Kay, R.W.; Stringer, J.;Smith, P.J.; Connaughton, C.; Shephard, J.D. Nanosecond laser textured superhydrophobic metallic surfaces and their chemical sensing applications. Appl. Surf. Sci. 2015, 357, 248-254. [CrossRef]

8. Zhao, M.; Li, W.; Wu, Y.; Zhao, X.; Tan, M.; Xing, J. Performance investigation on different designs of superhydrophobic surface texture for composite insulator. Materials 2019, 12, 1164. [CrossRef]

9. Yang, Z.; Wang, L.; Sun, W.; Li, S.; Zhu, T.; Liu, W.; Liu, G. Superhydrophobic epoxy coating modified by fluorographene used for anti-corrosion and self-cleaning. Appl. Surf. Sci. 2017, 401, 146-155. [CrossRef]

10. Wang, N.; Xiong, D.; Deng, Y.; Shi, Y.; Wang, K. Mechanically robust superhydrophobic steel surface with anti-icing, uv-durability, and corrosion resistance properties. ACS Appl. Mater. Interfaces 2015, 7, 6260-6272. [CrossRef]

11. Lee, Y.S.; Lim, Y.T.; Choi, W.S. One-step synthesis of environmentally friendly superhydrophilic and superhydrophobic sponges for oil/water separation. Materials 2019, 12, 1182. [CrossRef] [PubMed]

12. Li, J.; Shi, L.; Chen, Y.; Zhang, Y.; Guo, Z.; Su, B.; Liu, W. Stable superhydrophobic coatings from thiol-ligand nanocrystals and their application in oil/water separation. J. Mater. Chem. 2012, 22, 9774-9781. [CrossRef] 
13. Sun, Z.; Liao, T.; Liu, K.; Jiang, L.; Kim, J.; Dou, S. Fly-eye inspired superhydrophobic anti-fogging inorganic nanostructures. Small 2014, 10, 3001-3006. [CrossRef]

14. Lai, Y.; Tang, Y.; Gong, J.; Gong, D.; Chi, L.; Lin, C.; Chen, Z. Transparent superhydrophobic/superhydrophilic $\mathrm{TiO}_{2}$-based coatings for self-cleaning and anti-fogging. J. Mater. Chem. 2012, 22, 7420-7426. [CrossRef]

15. Jung, Y.; Bhushan, B. Mechanically durable carbon nanotube-composite hierarchical structures with superhydrophobicity, self-sleaning, and low-drag. ACS Nano 2009, 3, 4155-4163. [CrossRef]

16. Daniello, R.; Waterhouse, N.E.; Rothstein, J.P. Drag reduction in turbulent flows over superhydrophobic surfaces. Phys. Fluids 2009, 21, 085103. [CrossRef]

17. Song, J.; Wang, D.; Hu, L.; Huang, X.; Chen, Y. Superhydrophobic surface fabricated by nanosecond laser and perhydropolysilazane. Appl. Surf. Sci. 2018, 455, 771-779. [CrossRef]

18. Meng, H.; Wang, S.; Xi, J.; Tang, Z.; Jiang, L. Facile means of preparing superamphiphobic surfaces on common engineering metals. J. Phys. Chem. C 2008, 112, 11454-11458. [CrossRef]

19. Xue, C.; Jia, S.; Chen, H.; Wang, M. Superhydrophobic cotton fabrics prepared by sol-gel coating of $\mathrm{TiO}_{2}$ and surface hydrophobization. Sci. Technol. Adv. Mater. 2008, 9, 035001. [CrossRef]

20. Xu, Q.; Mondal, B.; Lyons, A.M. Fabricating superhydrophobic polymer surfaces with excellent abrasion resistance by a simple lamination templating method. ACS Appl. Mater. Interfaces 2011, 3, 3508-3514. [CrossRef]

21. Ma, M.; Mao, Y.; Gupta, M.; Gleason, K.K.; Rutledge, G.C. Superhydrophobic fabrics produced by electrospinning and chemical vapor deposition. Macromolecules 2005, 38, 9742-9748. [CrossRef]

22. Han, D.; Steckl, A.J. Superhydrophobic and oleophobic fibers by coaxial electrospinning. Langmuir 2009, 25, 9454-9462. [CrossRef]

23. Wang, B.; Hua, Y.; Ye, Y.; Chen, R.; Li, Z. Transparent superhydrophobic solar glass prepared by fabricating groove-shaped arrays on the surface. Appl. Surf. Sci. 2017, 426, 957-964. [CrossRef]

24. Gao, J.; Li, Y.; Li, Y.; Liu, H.; Yang, W. Fabrication of superhydrophobic surface of stearic acid grafted zinc by using an aqueous plasma etching technique. Cent. Eur. J. Chem. 2012, 10, 1766-1772. [CrossRef]

25. Hejazi, I.; Hajalizadeh, B.; Seyfi, J.; Sadeghi, G.M.M.; Jafari, S.H.; Khonakdar, H.A. Role of nanoparticles in phase separation and final morphology of superhydrophobic polypropylene/zinc oxide nanocomposite surfaces. Appl. Surf. Sci. 2014, 293, 116-123. [CrossRef]

26. Salman, S.M.; Salama, S.N.; Abo-Mosallam, H.A. Crystallization characteristics and physico-chemical properties of glass-ceramics based on $\mathrm{Li}_{2} \mathrm{O}-\mathrm{ZnO}-\mathrm{SiO}_{2}$ system. Bol. Soc. Esp. Ceram. Vidr. 2007, 56, $205-214$. [CrossRef]

27. Guo, X.; Cai, X.; Song, J.; Yang, G.; Yang, H. Crystallization and microstructure of CaO-MgO- $\mathrm{Al}_{2} \mathrm{O}_{3}-\mathrm{SiO}_{2}$ glass-ceramics containing complex nucleation agents. J. Non Cryst. Solids 2014, 405, 63-67. [CrossRef]

28. Partyka, J. Effect of $\mathrm{BaO}$ ratio on the structure of glass-ceramic composite materials from the $\mathrm{SiO}_{2}-\mathrm{Al}_{2} \mathrm{O}_{3}-\mathrm{Na}_{2} \mathrm{O}-\mathrm{K}_{2} \mathrm{O}-\mathrm{CaO}$ system. Ceram. Int. 2015, 41, 9337-9343. [CrossRef]

29. Xu, M.; Feng, Y.; Li, Z.; Wang, X.; Li, C.; Jiang, H.; Chen, Y. A novel, efficient and cost-effective synthesis technique for the development of superhydrophobic glass surface. J. Alloys Compd. 2019, 781, 1175-1181. [CrossRef]

30. Ji, H.; Chen, G.; Yang, J.; Hu, J.; Song, H.; Zhao, Y. A simple approach to fabricate stable superhydrophobic glass surfaces. Appl. Surf. Sci. 2013, 266, 105-109. [CrossRef]

31. Liu, L.; Zhao, J.; Zhang, Y.; Zhao, F.; Zhang, Y. Fabrication of superhydrophobic surface by hierarchical growth of lotus-leaf-like boehmite on aluminum foil. J. Colloid Interface Sci. 2011, 358, 277-283. [CrossRef] [PubMed]

32. Mazdiyasni, K.S. Powder synthesis from metal-organic precursors. Ceram. Int. 1982, 8, 42-56. [CrossRef]

33. Yoldas, B.E. Effect of variation in polymerized oxides on sintering and crystalline transformations. J. Am. Ceram. Soc. 1977, 65, 387-393. [CrossRef]

34. Sakka, S.; Kamiya, K. Glasses from metal alcoholates. J. Non Cryst. Solids 1980, 42, 403-422. [CrossRef]

35. Colomban, P. Gel technology in ceramics, glass-ceramics and ceramic-ceramic composites. Ceram. Int. 1989, 15, 23-50. [CrossRef]

36. Arkles, B. Tailoring surfaces with silanes. Chemtech 1977, 7, 766-778. 
37. Yuan, S.; Pehkonen, S.O.; Liang, B.; Ting, Y.; Neoh, K.G.; Kang, E.T. Superhydrophobic fluoropolymer-modified copper surface via surface graft polymerisation for corrosion protection. Corros. Sci. 2011, 53, 2738-2747. [CrossRef]

38. Zhu, X.; Zhang, Z.; Xu, X.; Men, X.; Yang, J.; Zhou, X.; Xue, Q. Facile fabrication of a superamphiphobic surface on the copper substrate. J. Colloid Interface Sci. 2012, 367, 443-449. [CrossRef] 